\title{
Analysis of Variation in Properties and its Impact on Heat Transfer in Sub and Supercritical Conditions of Water/Steam
}

\author{
R. Dhanuskodi, A. Arunagiri and N. Anantharaman
}

\begin{abstract}
Thermal power plants use water and steam as main working medium. The properties of water and steam depend on operating pressure and temperature. The present work analyses the variation in heat transfer due to changes in properties of water and steam such as, dynamic viscosity, specific heat, density and thermal conductivity in the pressure and temperature ranges of 100 to 1000 bar and 5 to $700^{\circ} \mathrm{C}$ respectively. Microsoft Excel version of IAPWS IF-97 (The International Association for the Properties of Water and Steam Industrial Formulation-97), has been used for invoking the transport properties for the given pressure and temperature. Trends of predominant properties in the above mentioned pressure and temperature ranges have been plotted and analyzed. The variation in heat transfer coefficients, calculated using Dittus Boelter equation, for a typical case has also been plotted. The present work gives an idea for heat transfer equipment designers about the conditions to be carefully handled to avoid metal temperature increase and the conditions that could be exploited to gain maximum heat transfer for cooling applications. The study also identifies the critical zones of property variations in sub and supercritical conditions which have direct impact on heat transfer.
\end{abstract}

Index terms-Property variation, water/steam, supercritical conditions, heat transfer

\section{INTRODUCTION}

Nomenclature:

$\mathrm{H} \quad$ convective heat transfer coefficient, $\mathrm{W} / \mathrm{m}^{2}{ }^{\circ} \mathrm{C}$

Q rate of heat transfer, $\mathrm{W}$

An area of heat transfer, $\mathrm{m}^{2}$.

$\mathrm{T}$ temperature, ${ }^{\circ} \mathrm{C}$

$\mathrm{Nu} \quad$ Nusselt number

K thermal conductivity of fluid film, W/m-K

$\mathrm{D}$ inner diameter of pipe in $\mathrm{m}$

Re Reynolds number $\left(V^{*} d^{*} \rho / \mu\right)$

Pr Prandtl number $\left(\mu^{*} \mathrm{Cp} / \mathrm{k}\right)$

$\mathrm{V}$ flow velocity, $\mathrm{m} / \mathrm{s}$

D hydraulic diameter $(4 *$ cross sectional area/wetted perimeter), $\mathrm{m}$

Manuscript received on June 27, 2011; revised September 22, 2011 .This work was supported in part by National Institute of Technology, Trichy, India.

R.Dhanuskodi, is with National Institute of Technology, Trichy 620015 , India, as research scholar and is working at BHEL, Trichy 620014, India. (phone: 91-9442502593; fax: 91-431-2520696; e-mail: dhanuskodi@bheltry.co.in).

A. Arunagiri is with the National Institute of Technology, Trichy, 620014, India as Associate / Assistant Professor (e-mail: aagiri@nitt.edu).

N. Anantharaman is with the National Institute of Technology, Trichy, 620014, India as Professor (e-mail: naraman@ nitt.edu)
L length of heated channel, $\mathrm{m}$

$\mathrm{C}_{\mathrm{p}} \quad$ specific heat at constant pressure, $\mathrm{J} / \mathrm{kg}-{ }^{\circ} \mathrm{C}$

Subscripts

s surface

b bulk

Greek letters

$\rho \quad$ Density of fluid, $\mathrm{kgm}^{-3}$

$\mu \quad$ Dynamic viscosity, pa.s

Heat transfer is an important phenomenon which takes place in many industrial applications. Hence, it is necessary for one to effectively manage it to achieve economy in operation. Among the three modes of heat transfer, the convective heat transfer plays an important role in industrial heat transfer applications. The convective heat transfer depends on the transport properties of fluids.

Thermal power plants use water and steam as working fluid. Heat produced through combustion of fuels, heats the outer surface of the tubes either by radiation or by convection. This heat gets transferred further into the inner surface of the tube by conduction through the wall material of the tube. Water or steam passing through the tube, receives this heat by convection and maintain metal temperature within the acceptable limits if the convective heat transfer coefficient is sufficient. The magnitude of the variation in convective heat transfer coefficient depends on the operating variables, physical properties of fluid and the physical dimensions of the flow paths. Changes in flow path have an impact on the dynamics of flow whereas; the variation in pressure and temperature affect the properties of the fluid. Literatures [1-5] have discussed about this property variation, literatures [5-12] have reported the variation in heat transfer coefficient due this property variation and literatures [1], [2], [5] and [9-15] have reported the impact in terms of wall temperature variation indicating that changes in fluid properties have a great impact on the heat transfer behavior.

The objective of the present work is to study the changes in properties of water/steam over a wide range of boiler operating conditions and observe their impact on heat transfer for a selected tube and flow. The computerized excel version (X Steam Tables) of the steam properties of IAPWS IF-97 (The International Association for the Properties of Water and Steam Industrial Formulation-97) and the standard Dittus Boelter heat transfer correlation have been used in this analysis. Graphical trends of the variation in various properties of water/steam with changes in pressure and temperature and their impact on variation in heat transfer coefficient have been discussed in detail in this paper. 


\section{Convective HeAt TRANSFER}

Convection is the transfer of thermal energy by the movement of molecules from one region to another. As fluid moves more quickly, the convective heat-transfer increases. The presence of bulk motion of fluid enhances the heat transfer between the solid surface and the fluid.

The rate of convective heat transfer is given by,

$$
\mathrm{Q}=\mathrm{hA}\left(\mathrm{T}_{\mathrm{s}}-\mathrm{T}_{\mathrm{b}}\right)
$$

The interest of a designer would be to compute the wall temperature for a given heat flux and fluid condition in order to select appropriate material or for avoiding operating conditions that would over heat the tube metal. It is possible to compute the wall temperature using Eq. (1), if the heat transfer coefficient ' $h$ ', is known.

Convective heat transfer coefficient ' $h$ ' is given by the following relationship,

$$
\mathrm{h}=\mathrm{Nu} * \mathrm{k} / \mathrm{d}
$$

The heat transfer coefficient ' $h$ ' depends on physical properties of the fluid such as temperature and the physical situation in which convection occurs. Therefore, the heat transfer coefficient must be derived or found experimentally for every system analyzed. Many correlations developed based on experiments, each applicable to specific range of conditions, are available in literatures [2, 4]. As shown in equation (2), the heat transfer coefficient is a function of Nusselt number and fluid properties. Hence, all the experimental correlations exhibit a relationship for Nusselt number with other non dimensional numbers and fluid properties. Most of these correlations require both wall temperature and bulk fluid temperature for computing Nusselt number and are applicable for specific conditions. The Dittus Boelter equation is the one which is applicable for a wide range of single phase fluid conditions and require only the bulk fluid temperature for computation of Nusselt number. Hence, this equation has been chosen for the present analysis to understand the impact of change in fluid property on heat transfer.

The Nusselt number as proposed by Dittus Boelter is given by the following relationship

$$
\mathrm{Nu}=0.023 * \operatorname{Re}^{0.8} * \operatorname{Pr}^{0.4}
$$

In general, the Dittus-Boelter correlation is valid for single-phase heat transfer in channels within the following range:

$$
0.7 \leq \operatorname{Pr} \leq 160 ; \operatorname{Re} \geq 10,000 ; \text { and } L / D \geq 10
$$

For the study in this paper, $\operatorname{Pr}$ is 0.716 to 13.733 ; $\operatorname{Re}$ is 100,762 to $1,334,535$; and $L / D$ is 731.7 .

\section{ANALysis OF PRoperty VARIATION OF WATER/StEAM}

The variations of properties of water/steam with operating conditions especially at different temperature and pressure conditions were analyzed using Excel based $\mathrm{X}$ Steam Tables software. The transport properties and Prandtl number were plotted against temperature at various levels of pressure and are shown in figures 1 to 7.

\section{A. Variation in Dynamic Viscosity}

As observed in figure 1(a), the dynamic viscosity decreases hyperbolically with increase in temperature up to saturation / psuedocritical tempearture corresponditng to each pressure and it gradually increases with increase in temperature after saturation / psuedocritical tempearture, as shown in figure $1(\mathrm{~b})$.

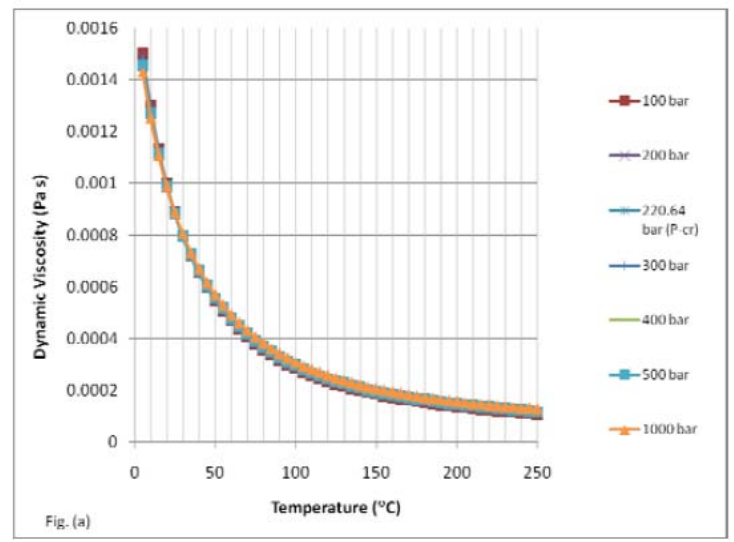

Fig.1 (a) Influence of Temperature and Pressure on Dynamic Viscosity of Water/Steam up to $250^{\circ} \mathrm{C}$

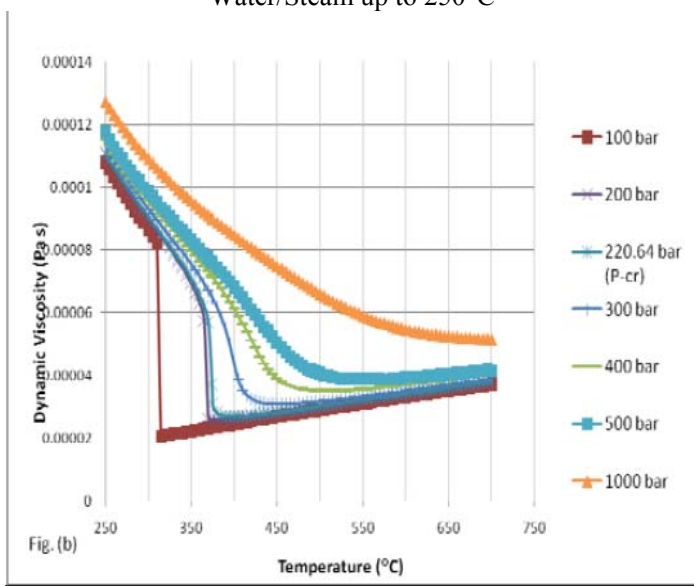

Fig. 1 (b) Influence of Temperature and Pressure on Dynamic Viscosity of Water/Steam above $250^{\circ} \mathrm{C}$

As observed in both the figures, viscosity increases with increase in pressure, but the predominant effect is observed only with change in temperature. From this, it is inferred that considering the variation in dynamic viscosity, increase in temperature reduces Prandtl number and increases Reynolds number upto saturation /critical/psuedocritical tempearture. After that, increase in temperature gradually increases Prandtl number and reduces Reynolds number. Also, increase in pressure increases Prandtl number and decreases Reynolds number. This is due to the fact that Reynolds number is inversely proportional to viscosity and Prandtl number is directly proportional to viscosity.

\section{B. Variation in Specific Heat at Constant Pressure}

As observed in figures 2(a) and 2(b), the specific heat has the highest value at the critical pressure and temperature of 220.64 bar and $373.95^{\circ} \mathrm{C}$ respectively. At all the other pressures, specific heat is maximum at the respective saturation / psuedocritical tempearture. In general, specific heat before saturation / psuedocritical temperature are higher than that after such temperature.

With increase in pressure, the specific heat value decreases upto saturation/pseudocritical temperature and it increases considerably with increase in pressure after saturation / psuedocritical tempearture. As the specific heat increases directly with temperature up to saturation / pseudocritical temperature, prandtl number varies directly 
with variation in specific heat.

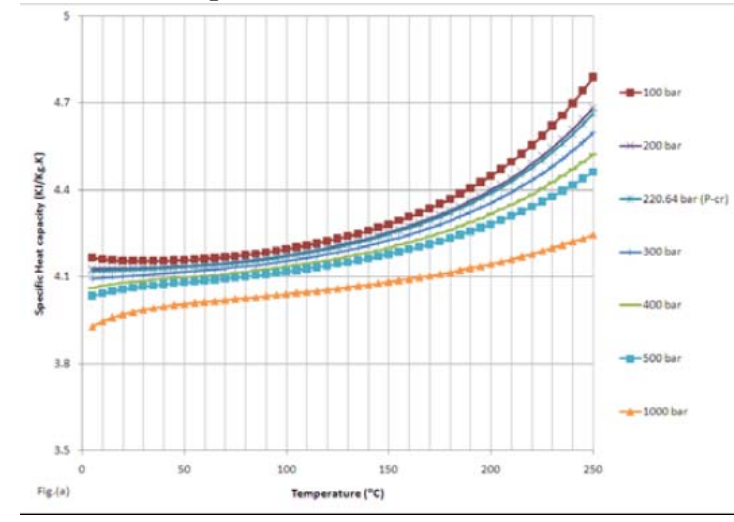

Fig. 2. (a) Influence of Temperature and Pressure on Specific Heat at Constant Pressure of Water/Steam up to $250^{\circ} \mathrm{C}$

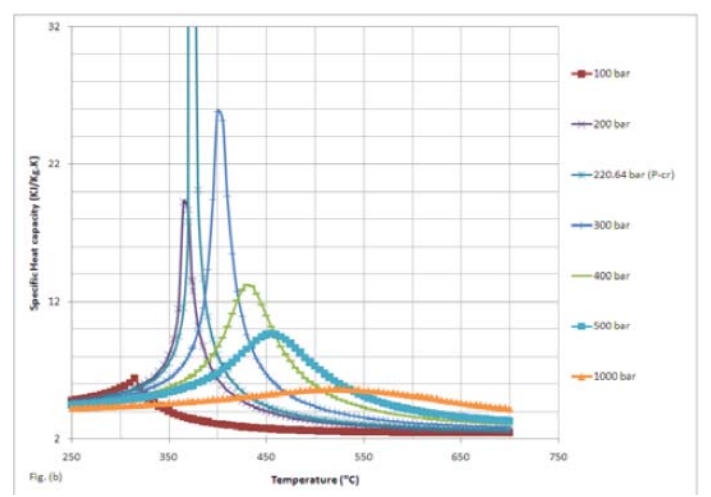

Fig. 2. (b) Influence of Temperature and Pressure on Specific Heat at Constant Pressure of Water/Steam above $250^{\circ} \mathrm{C}$

\section{Variation in Thermal Conductivity}

As shown in figures 3(a) and 3(b), at all pressures, the thermal conductivity increases up to around $150^{\circ} \mathrm{C}$ and then decreases considerably up to saturation / pseudo critical temperature and increases gradually after saturation / pseudo critical temperature. Also, it peaks at critical point and then drops subsequently.

At a particular temperature, thermal conductivity is higher at higher pressure. Since the Prandtl number is inversely proportional to thermal conductivity, the Prandtl number at temperatures above saturation and pseudo critical conditions would be higher than that at temperatures below saturation / pseudo critical condition. Also, for the same temperature, the Prandtl number for higher pressures will be lower because of the increase in thermal conductivity with increase in pressure.

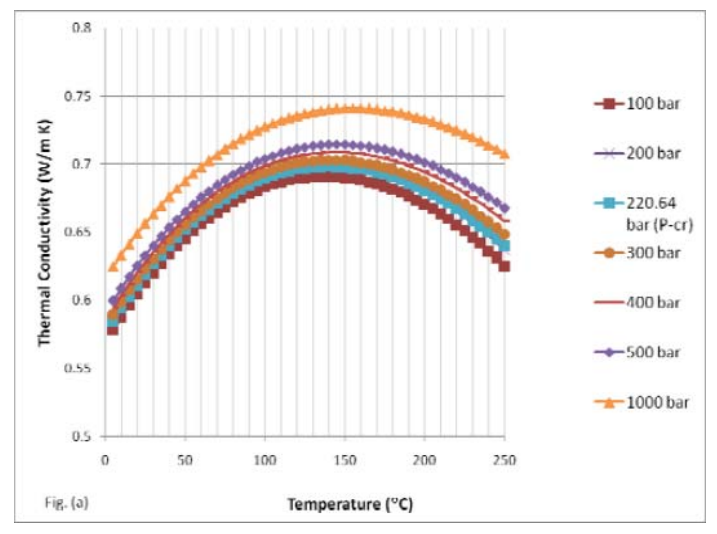

Fig. 3 (a) Influence of Temperature and Pressure on Thermal Conductivity of Water/Steam up to $250^{\circ} \mathrm{C}$

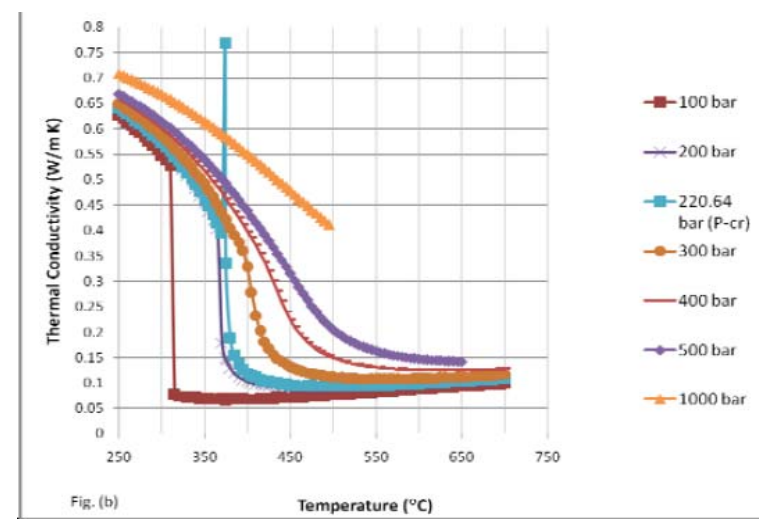

Fig. 3 (b) Influence of Temperature and Pressure on Thermal Conductivity of Water/Steam above $250^{\circ} \mathrm{C}$

\section{Variation in Prandtl Number}

In sections 3.1 to 3.3 , the effects of temperature and pressure on dynamic viscosity, specific heat and thermal conductivity individually have been discussed. Figures 4(a) and 4(b) show the effect of temperature and pressure on Prandtl number, which is a function of viscosity, specific heat and thermal conductivity.

The trend seems to be matching predominantly with those of dynamic viscosity and specific heat. It hyperbolically reduces up to $250^{\circ} \mathrm{C}$, and then gradually rises to peak value at saturation/critical/pseudo critical temperature and gradually falls as seen in the figures 4(a) and 4(b). Prandtl number is around 1 for all pressures at temperatures above $600^{\circ} \mathrm{C}$.

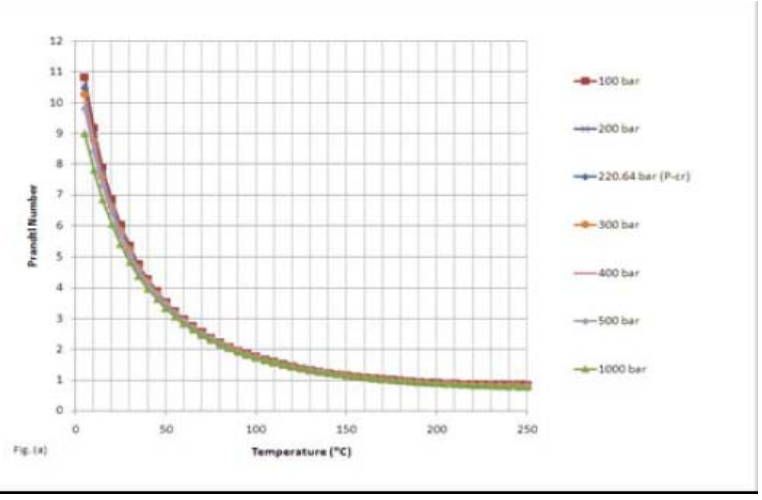

Fig. 4. (a) Influence of Temperature and Pressure on Prandtl Number of Water/Steam up to $250^{\circ} \mathrm{C}$

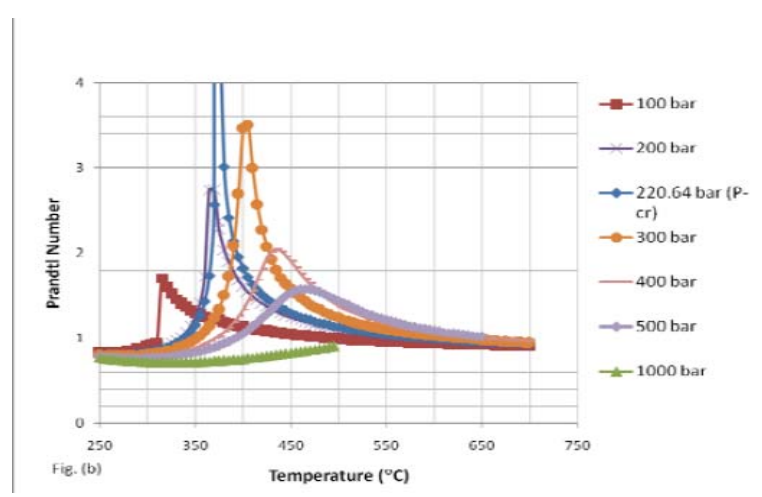

Fig. 4. (b) Influence of Temperature and Pressure on Prandtl Number of Water/Steam above $250^{\circ} \mathrm{C}$

\section{E. Variation in Density}

Figures 5(a) and 5(b) indicate the trends of density variation with changes in temperature and pressure. As seen in these figures, under subcritical pressure conditions 
( $\mathrm{P}<220.64$ bar), the density change is the highest at saturation temperature and is comparatively higher above saturation temperature than that below saturation temperature.

In supercritical condition ( $\mathrm{P}>220.64$ bar), the density change is minimum and it becomes much lower (almost linear) at higher pressures. It implies that for the same mass flow rate, the pressure drop at higher pressure conditions would be minimal. Decrease in density and increase in specific volume results in increase in Reynolds number.

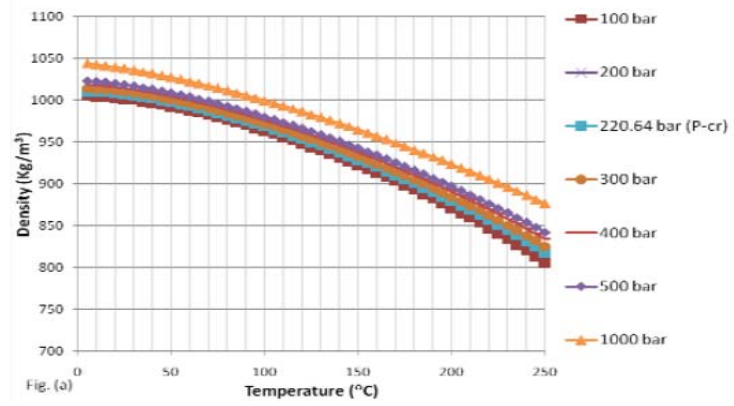

Fig. 5 (a) Influence of Temperature and pressure on Density of Water/Steam up to $250^{\circ} \mathrm{C}$

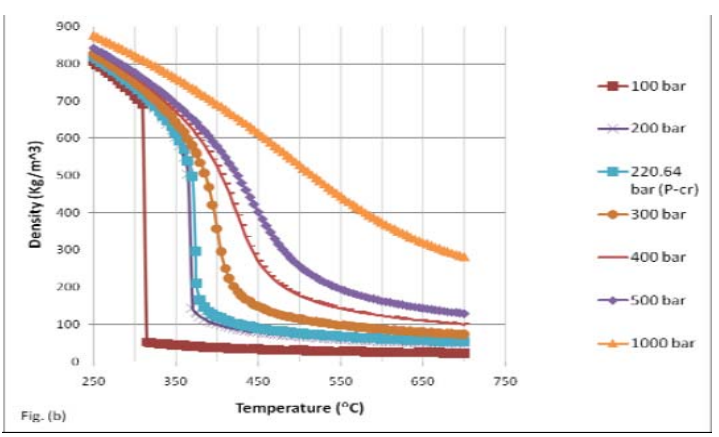

Fig. 5 (b) Influence of Temperature and pressure on Density of Water/Steamabove $250^{\circ} \mathrm{C}$

\section{F. Property Variation under Typical Sub-critical and Supercritical Conditons}

For better understanding of the property variation, figures 6(a) and 6(b) indicate the variation of specific heat, thermal conductivity and Prandtl number for sub critical and supercritical condition respectively and figures 7(a) and 7(b) indicate the variation of density and dynamic viscosity, for sub- critical and supercritical condition respectively.

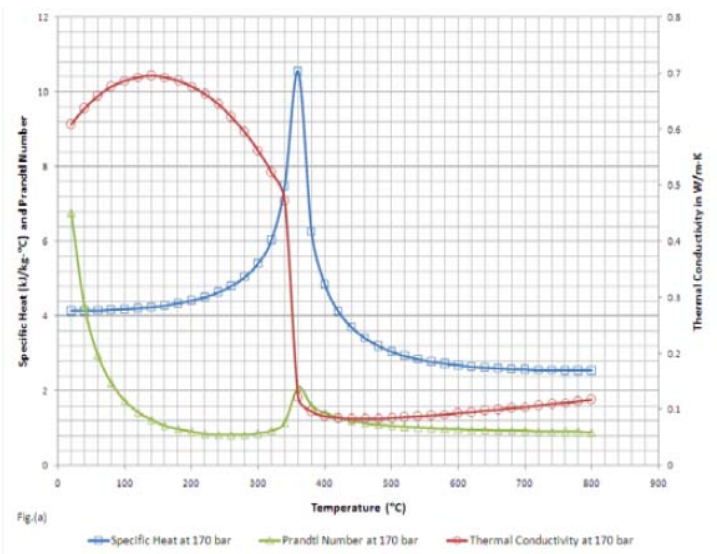

Fig. 6 (a) Influence of Temperature and pressure on specific heat, thermal conductivity and Prandtl number at sub critical conditions of Water/Steam

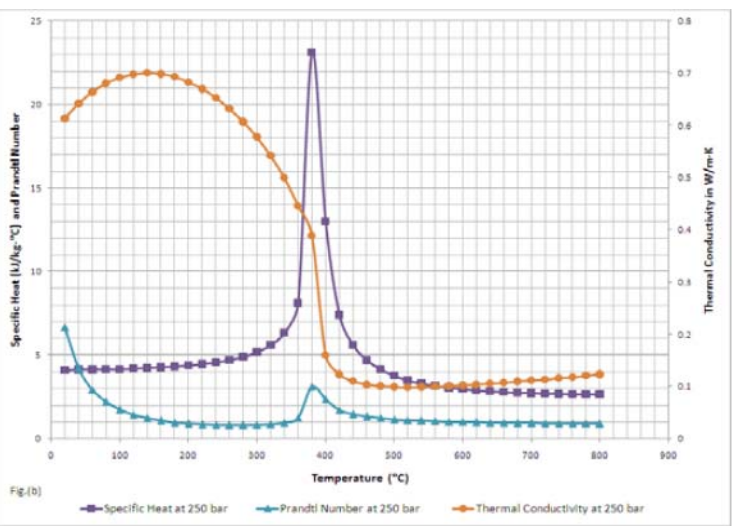

Fig. 6 (b) Influence of Temperature and pressure on specific heat, thermal conductivity and Prandtl number at supercritical conditions of Water/Steam

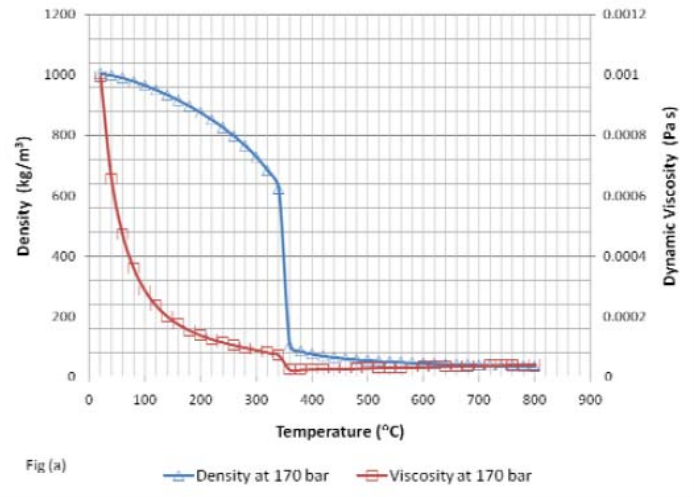

Fig. 7 (a) Influence of Temperature and pressure on density and dynamic viscosity at sub critical conditions of Water/Steam

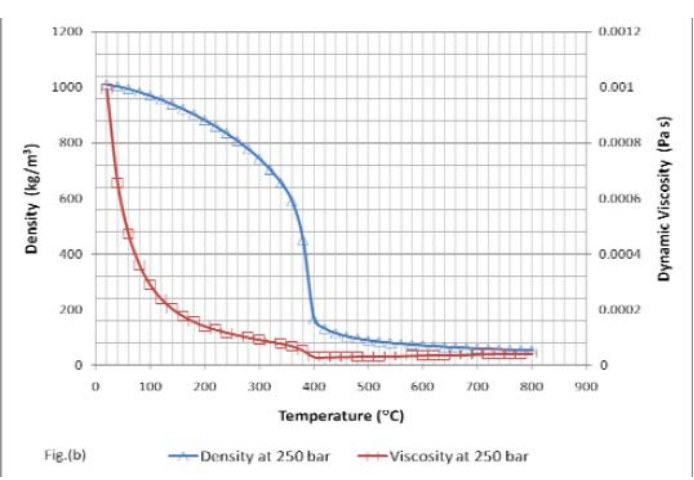

Fig. 7 (b) Influence of Temperature and pressure on density and dynamic viscosity at supercritical conditions of Water/Steam

\section{G. Variation in Reynolds Number}

Reynolds number also influence heat transfer coefficient. This number is directly proportional to flow velocity, inner diameter of the pipe and density. It is inversely proportional to dynamic viscosity.

\section{IMPACT ON HEAT TRANSFER}

As mentioned earlier in section 2.0, the convective heat transfer is directly proportional to heat transfer area, difference in temperature between heating wall and heat receiving fluid and heat transfer coefficient. For fixed area and temperature difference, heat transfer is mainly a function of heat transfer coefficient.

The analysis of these equations clearly indicate that the heat transfer cofficient would definitely be affected by the 
changes in fluid properties viz., dynamic viscosity, specific heat, thermal conductivity and density which vary depending on the pressure and temperature conditions. A trial calculation for a pipe of $0.0082 \mathrm{~m}$ inner diameter and a flow rate of $0.2 \mathrm{~kg} / \mathrm{s}$ was made to give a feel on the variation of this heat transfer coefficients with changes in pressure and temperature and the trends are shown in figures 8(a) and 8(b).

As seen in the figure $8(\mathrm{~b})$, for the selected case, the heat transfer coefficient is maximum at critical pressure and temperature. For any pressure, the heat transfer coefficient has the peak value at saturation/critical/psuedo critical temperature. Also, at any pressure, the heat transfer coefiicient below saturation/critical/psuedo critical temperature is always higher than that above saturation/critical/psuedo critical temperature. Higher the pressure, higher would be the heat transfer coefficient. Also, at higher pressures in the supercritical regime, the variaton in heat transfer coeffient with variation in temperature is minimum. This could be advantageously used in heat transfer applications and the design of heat exchanger equipment.

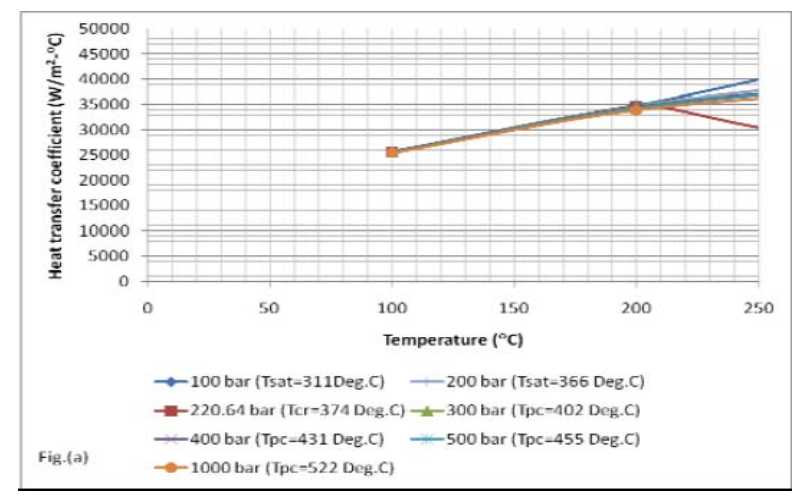

Fig. 8 (a) Variation in Heat transfer Coefficient up to $250^{\circ} \mathrm{C}$ for a typical flow in a pipe (Indicating the impact of variation in the properties of fluid)

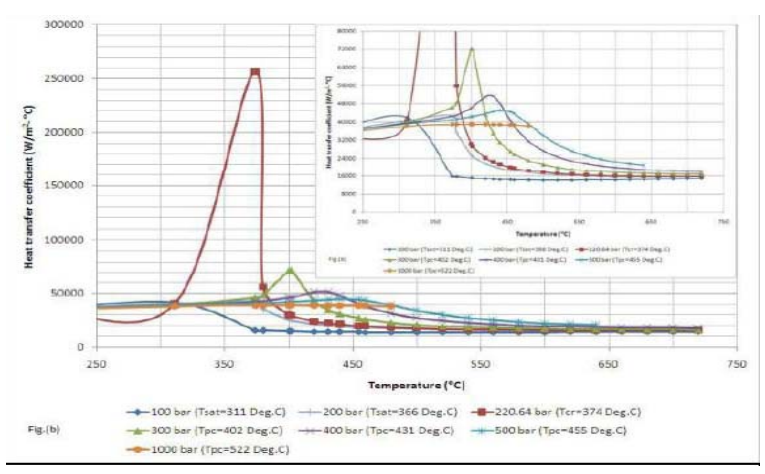

Fig. 8 (b) Variation in Heat transfer Coefficient above $250^{\circ} \mathrm{C}$ for a typical flow in a pipe (Indicating the impact of variation in the properties of fluid)

\section{CONCLUSION}

In this paper, an understanding of the variation in predominant fluid (water/steam) properties like dynamic viscosity, specific heat at constant pressure, thermal conductivity and density and their impact on heat transfer coefficient at various pressures and temperatures have been discussed. The results could be judiciously used by designers of heat exchangers. The zones of high specific heat and increased heat transfer coefficient could be used for applications where cooling is of high importance. The understanding of the zones of poor heat transfer coefficients, enables the designer to select suitable materials to withstand the temperature while designing heat exchangers.

It is clear from figures 1 to 5 that the impact of temperature on transport properties falls distinctly under three categories viz, subcritical, critical and supercritical. The changes are found dramatic at saturation temperature at sub-critical state, at critical temperature in critical state and at pseudo-critical temperature in supercritical state. The variation in properties is predictable under sub-critical conditions up to saturation temperature and far from pseudo critical temperature in supercritical condition where they follow a defined trend. The changes in properties at saturation, critical and pseudo critical temperatures are dramatic and their impact on heat transfer is complex. Analytical treatments of these conditions may not be yielding dependable results. Hence, correlations need to be developed for these regimes based on experimental investigations.

\section{REFERENCES}

[1] X. Cheng, T.Schulenberg, Heat transfer at Supercritical Pressures literature Review and Application to an HPLWR (2001)

[2] F.Roelofs-CFD Analysis of Heat transfer to Supercritical Water Flowing Vertically Upward in a Tube, Report 21353/04.60811/P, prepared under the contract of the Netherlands Ministry of Economic Affairs- (Petten 1 December 2004)

[3] S.Koshizuka, N.Takano and Y.Oka, Numerical Analysis of Deterioration Phenomina in Heat Transfer to Supercritical Water, International Journal of Heat Mass Transfer, Great Britain, Pergaman Press 1995, Vol.38, pp 3077-3084

[4] M.A.Styrikovitch, T.Kh.Margulova and Z.L.Miropol'Skii, 'Problems in the Development of Designs of Supercritical Boilers', Teploenergetika, 1967, 14(6) 4-7

[5] K.Yamagata, K.Nshikawa, S.Hasegawa, T.Fujii and S.Yoshida, 'Forced Convective Heat Transfer to Supercritical Water Flowing in Tubes', International Journal of Heat Mass Transfer, Great Britain, Pergaman Press 1972, Vol.15, pp 2575-2593

[6] E.S.Vlakhov, A.L.Miropolski, L.R.Khasanov-Agaev, 'Heat transfer to a Supercritical Medium with Mixed Convection and Rising Flow in Heated Tubes' Thermal Engineering, 1981, 28 (11)

[7] O.K.Smirnov, S.N.Krasnov, 'An Investigation of Unsteady Heat Transfer to Water at Supercritical Pressures, Teploenergetika, 1978, 25(4) 86-87

[8] N.S. Kondrat' EV, Heat Transfer and Hydraulic Resitance in Supercritical Water Flowing in Tubes, Teploenergetika, 1969, 16(8) 49-51

[9] M.E.Shitsman, Temperature Conditions in Tubes at Supercritical Pressures, Teploenergetika, 1968, 15(5) 57-61

[10] L.U.Krasyakova, I.I.Belyakov and N.D.Fefelova, 'Heat Transfer with a Downward Flow of Water at Supercritical Pressure' Heat Transfer

[11] I.I.Belyakov, L.Yu.Krasyakova, A.V.Zhukovskii and N.D.Fefelova, 'Heat Transfer in Vertical Risers and Horizontal Tubes at Supercritical Pressure', Teploenergetika, 1971, 18 (11) 39-43

[12] David Palko and Hendryk Anglart, Theoritical and Numerical Study of Heat Transfer in High Performance Light Water Reactor, Science and Technology of Nuclear Installations, Hidwi Publishing Corporation, 2008, Vol 2008, Article ID 405072, doi:10.1155/405072

[13] B.Shiralkar and P.Griffith, The Effect of Swirl, Inlet Conditions, Flow Direction and Tube Diameter on the Heat Transfer to Fluids at Supercritical Pressures, Journal of Heat Transfer, August 1970, pp. 465-474

[14] J.W.Ackerman, 'Pseudoboiling Heat Transfer to Supercritical Pressure Water in Smooth and Ribbed Tubes, Transactions of ASME, August 1970, pp. 490-498

[15] Yu.Vikhrev, Yu.D.Barulin and A.S.Kon'Kov, 'A Study of Heat Transfer in Vertical Tubes at Supercritical Pressures, Teploenergetika, 1967, 14 (9) 80-82 


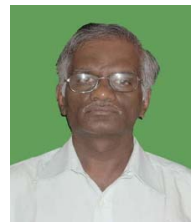

R.Dhanuskodi: Virudhunagar, Tamil Nadu, India, 15th May 1958. BE, Mechnical Engg., REC, Trichy, Tamil Nadu, India, 1985. M.Tech, Energy Engg., REC, Trichy, Tamil Nadu, India, 1995.

Having worked under various positions up to the present position of senior manager in BHEL, Trichy, India, he has gained experience in establishing $R \& D$ test facilities for the evaluation of fireside performance of boiler fuels \& blends and evaluation of supercritical heat transfer. He was involved in the development of smart wall blowing system for pulverized coal fired boilers. He is the co-inventor for 5 patents, 13 copy rights and 2 design registrations. As a co author, he has published the following papers:

Paper titled "Pilot Scale Boiler Simulated Fireside Testing of Fuels" presented in the National Seminar on "Coal \& Coal Combustion in Utility Boilers" held during 6th to 8th April, 1999 at R\&D Center, National Thermal Power Corporation, Noida, India.

An article titled "Combustion and Deposit Formation Behaviour on the Fireside Surfaces of a Pulverised Fuel Boiler Fired with a Blend of Coal and Petroleum Coke" published in Volume 175, Number 7 / July 2003 edition of the international journal Combustion Science and Technology. His present research work is in studying the heat transfer aspects of water at supercritical conditions.

A paper titled "Pilot Scale Fireside Performance Evaluation of Boiler Fuels" presented in the Sixth ISHMT-ASME Heat and Mass Transfer Conference sand Seventh National Heat and Mass Transfer Conference held during 5th to 7th January, 2004 at Indra Gandhi Center for Atomic Research, Kalpakkam, India

His present area of research interest is evaluation of heat transfer behavior of water at supercritical conditions

Mr.R.Dhanuskodi is a life member of Institution of Engineers (India) (Member No.M-111159-5) and The Combustion Institute (Member No.LMC-161). He has won a number of in-house BHEL awards including the BHEL's Excel award in the year 2003-04 under the best author category for the paper titled 'Pilot Scale Fireside Performance Evaluation of Boiler Fuels' published in the 6th ISHMT-ASME (17th National ISHMT) conference held at IGCAR, Kalpakkam, India, from 5th to 7 th January 2004.

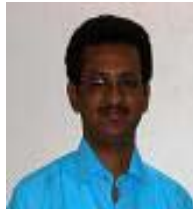

A. Arunagiri, Kolathur, Tamil Nadu, India, 20th May 1977. B. Tech., Chemical Engg., C.I.T., Coimbatore, Tamil Nadu, India, 1998. M. Tech, Chemical - Plant Design., REC, Trichy, Tamil Nadu, India , 2000, Ph.D., Chemical Engg., A. C. College of Tech., Anna University, Chennai, Tamil Nadu, India, 2006.

He is working as ASSISTANT PROFESSOR in the Dept. of Chem. Engg., NATIONAL INSTITUTE OF TECHNOLOGY, Trichy, Tamil Nadu, India, from 2006. He also worked as LECTURER at A. C. College of Technology, Anna University, Chennai, Tamil Nadu, India. He is a coauthor of 7 research articles and 15 conference papers in both national and international level.

1. Paper titled "Gas holdup and energy Dissipation in Liquid - Gas Ejectors" published in Jl. of Chem. Tech. \& Biotech., V-83, 10641071, 2008.

2. Paper titled "Synergistic Extraction of Acetic acid from its Aqueous Solution" published in Jl. of the University of Chem. Tech., \& Metallurgy" V-42, N-2, 423- 426, 2007.

3. Paper titled "Slip Velocity and gas phase holdup in Gas-Liquid Cocurrent Upflow through Packed Bed" published in Jl. of Chem. Engg. of Japan, V-38, 243 252, 2005.

His research interests are Transfer Operations, Environmental Engineering and Multiphase flow.

Dr. A. Arunagiri is a life member of Indian Institute of Chemical Engineers (LM-34030) and was awarded for Teaching Research Associate fellowship and Senior Research Fellowship by Anna University and CSIR respectively.

N.Anantharaman, Chennai, Tamil Nadu, India, $8^{\text {th }}$ May 1955. B.Tech. Chemical Engg., REC, Trichy, Tamil Nadu, India, 1977. M.E.,Chemial Engg., IISc., Bangalore, Karnataka, India , 1979.

Having started his career at REC, trichy as a senior Reserach fellow in

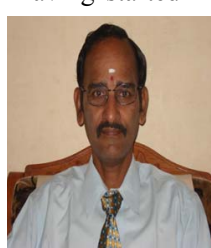
1979, he became lecturer in 1981 at RECT (NITT) and rose to the level of PROFESSOR and subsequently, DEAN (Academic) in 2010 in NITT Ever since, he joined in teaching profession, he has offered a number of courses both at Under graduate and Master's level. He was involved in offering laboratory courses. He has Co-authored three books, Process Calculations (2003, 2011), Elements of Mass transfer Part-1 (2005) and Mass Transfer Theory and Practice (2011), all published by PHI Learning Centre, New Delhi. Top his credit he has more than 80 publications in International/National Journals and Conferences.

N.Anantharaman is a life Fellow of Institution of Engineers (India) (Fellow No.F-017549-4/CH), Indian Society for Technical education(LM 3133), New Delhi, Life member of Indian Institute of Chemical Engineers(LM 24493), Kolkata and Life member of FMFP, Mumbai. He was awarded the best teacher by NITT in 2008. His paper on Removal of Chromium (VI) from aqueous solutions by Emulsion liquid membrane, presented in CHEMCON 2003 held at RRL, Bhubaneshwar in Dec 2003 was awarded the M A Shukla Prize for II best paper in 2004 in the IICh E annual session at Mumbai. He has also served in the Executive council of IE (India) Tiruchirappalli local Centre for more than 12 years. He is also member of the Board of studies in Chemical Engineering of various Universities and chaired technical sessions in national conferences 